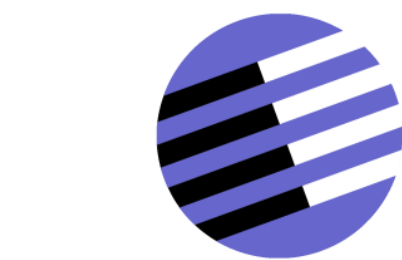

GOVERNANCE AND THE EFFICIENCY

OF ECONOMIC SYSTEMS

G E S Y

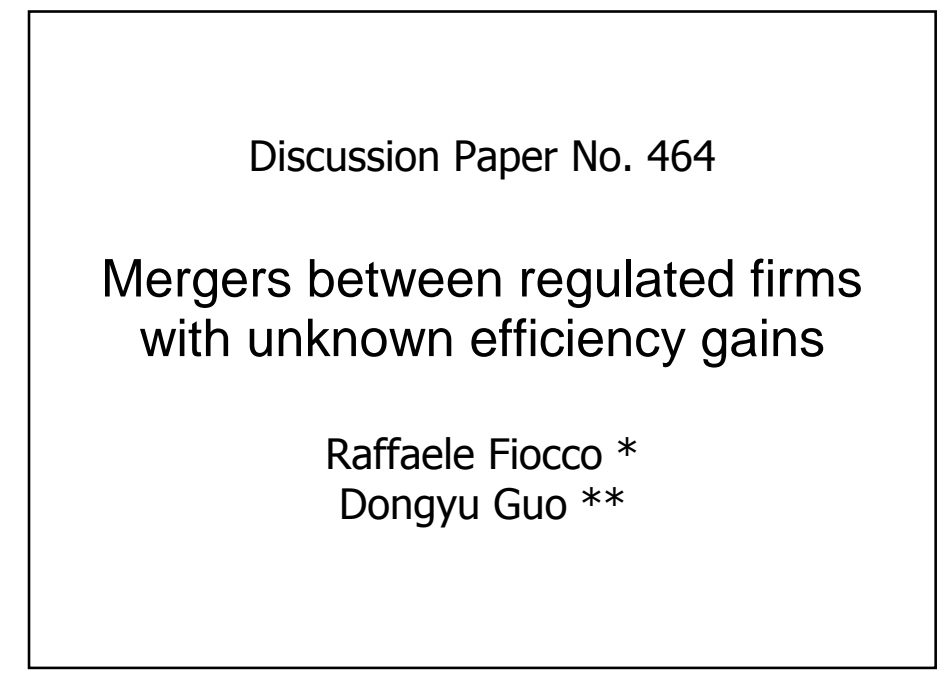

* Mannheim Centre for Competition and Innovation (MaCCl) and University of Mannheim

** Humboldt-Universität zu Berlin

August 2014

Financial support from the Deutsche Forschungsgemeinschaft through SFB/TR 15 is gratefully acknowledged.

Sonderforschungsbereich/Transregio $15 \cdot$ www.sfbtr15.de

Universität Mannheim · Freie Universität Berlin · Humboldt-Universität zu Berlin · Ludwig-Maximilians-Universität München Rheinische Friedrich-Wilhelms-Universität Bonn · Zentrum für Europäische Wirtschaftsforschung Mannheim

Speaker: Prof. Dr. Klaus M. Schmidt · Department of Economics · University of Munich · D-80539 Munich, Phone: $+49(89) 21802250 \cdot$ Fax: $+49(89) 21803510$ 


\title{
Mergers between regulated firms with unknown efficiency gains
}

\author{
Raffaele Fiocco* and Dongyu Guo ${ }^{\dagger}$
}

August 15, 2014

\begin{abstract}
In an industry where regulated firms interact with unregulated suppliers, we investigate the welfare effects of a merger between regulated firms when efficiency gains are uncertain before the merger and their realization becomes private information of the merged firm. The optimal merger policy trades off potential efficiency gains against regulatory distortions from informational problems. We show that, as a consequence of this trade-off, more intense competition in unregulated segments of the market induces a more lenient merger policy. However, the regulated firms' diversification into a competitive segment can lead to a more lenient merger policy when competition is weaker.
\end{abstract}

Keywords: asymmetric information, competition, efficiency gains, mergers, regulation. JEL Classification: D82, L43, L51.

${ }^{*}$ Mannheim Centre for Competition and Innovation (MaCCI) and University of Mannheim, Department of Economics, L7, 3-5, D-68131 Mannheim, Germany. Email address: raffaele.fiocco@uni-mannheim.de

${ }^{\dagger}$ Humboldt-Universität zu Berlin, Institute for Economic Theory I, Spandauer Str. 1, D-10178 Berlin, Germany. Email address: dongyu.guo.1@hu-berlin.de 


\section{Introduction}

The adequate antitrust scrutiny of mergers between firms is a relevant policy issue in modern countries. The US Horizontal Merger Guidelines (HMG), revised by the Department of Justice and the Federal Trade Commission in 2010, and the EC Merger Regulation reformed in 2004 acknowledge the relevance of cost synergies in merger control. Two major practical problems recognized by antitrust authorities and courts concern the uncertainty about the magnitude of efficiency gains before a merger takes place, and the merging firms' privileged information about the realization of efficiency gains. Antitrust authorities emphasize the issue of uncertainty, since "efficiencies projected reasonably and in good faith by the merging firms may not be realized" (HMG, Sect. 4). Moreover, as declared by Judge T. F. Hogan for the merger case of Staples and Office Depot, "the Court agrees with the defendants that where, as here, the merger has not yet been consummated, it is impossible to quantify precisely the efficiencies that it is will generate" (US District Court for the District of Columbia, Civ. No. 97-701). ${ }^{1}$

The presence of asymmetric information about post-merger costs has also been recognized in the merger debate, since "efficiencies are difficult to verify and quantify, in part because much of the information relating to efficiencies is uniquely in the possession of the merging firms" (HMG, Sect. 4). ${ }^{2}$ As Amir et al. (2009, p. 266) emphasize, "this first-to-know advantage thus emerges as a natural candidate for the fundamental asymmetry that mergers seem to trigger in favor of the merged firm".

The aim of this paper is to investigate the welfare effects of a merger between regulated firms, when efficiency gains from joint production are uncertain before the merger and their realization becomes private information of the merged entity.

Despite the relevance of this phenomenon, mergers in regulated industries have so far received little theoretical attention. Recent decades have witnessed merger waves in industries which are in large part under regulatory control, such as electricity, gas, sanitation, telecommunications, transportation and water. The US Regional Bell Operating Companies (RBOCs), which provide regulated local telephone services as a result of the 1984 divestiture of AT\&T, have engaged after the enactment of the Telecommunications Act of 1996 in a consolidation process, which has reduced their number from seven to only three. Kwoka and Pollitt (2010) report that in the US electricity industry more than 75 mergers occurred between 1994 and 2003, which affected half of the customers of all investor-owned electricity operating companies.

Since enterprises with large assets are usually involved, the relevance of this phenomenon in terms of resources is definitely high. E.ON, one of the world's largest electric utility providers, was created in 2000 as a result of the merger between Veba and Viag valued at about 14 billion dollars. The merger between Duke Energy and Progress Energy, realized in 2012 through a transaction of about 32 billion dollars, has generated the largest energy utility in the US by number of customers. ${ }^{3}$

\footnotetext{
${ }^{1}$ This conclusion is also supported by some empirical evidence. Motta (2004, Ch. 5, p. 242) states that "merging parties often have a genuine tendency to overstate the benefits from combining their activities and assets. Even strictly internal and confidential documents often report too optimistic an assessment of the merger's efficiency gains".

${ }^{2}$ Quotations with emphasis added can be found at http://justice.gov/atr/public/guidelines/hmg-2010.html.

${ }^{3}$ We refer to Cox and Portes (1998) for some relevant case studies of mergers in regulated industries.
} 
In recent decades, most regulated industries have been involved in a partial liberalization process, which has increased the scope for demand interconnections between regulated and unregulated goods. In the energy sector, transmission and distribution networks are typically regulated, while retail services are often open to competition. Regulated local telephone services coexist with unregulated telecommunications services, such as long-distance, broadband Internet and digital cable telephone services. Regulated railways companies operate in competition with unregulated long distance buses and airlines. In big cities, regulated public utilities run railways, subways and buses, while competitive firms supply alternative services such as car sharing or car rental.

In this paper, we characterize the optimal merger policy involving regulated firms, whose task is to find a balance between the benefits of potential efficiency gains from the merger and the costs of distortions in the regulatory policy due to the aforementioned informational problems about efficiency gains. We explore this trade-off in a setting where a merger occurs between two regulated firms that operate in two separate markets. As empirical evidence suggests, most mergers in regulated industries involve firms that are established in different regions, since they constitute local natural monopolies (e.g., electricity networks, local telephone services and local public transportation). Each regulated firm interacts with unregulated suppliers since there is some degree of substitutability or complementarity between regulated and unregulated goods. For the sake of concreteness, we consider two standard forms of competition, namely, Bertrand and Cournot competition, which are known to differ in the degree of intensity or toughness of product market competition.

We show that the intensity of competition in the unregulated part of the market affects the optimal merger policy. In particular, we find that, in the presence of uncertainty over post-merger costs before the merger occurs, Bertrand competition in the unregulated segment leads to a more lenient merger challenge rule than Cournot competition. To understand the rationale for this result, it is important to realize that, when post-merger costs are uncertain, an ex ante welfare-enhancing merger may eventually result in higher costs, namely, efficiency losses, driven for instance by clashes between corporate cultures (e.g., White 1987). ${ }^{4}$ In this case, even when post-merger costs become common knowledge, the regulated production is reduced because regulated activities are more inefficient. Since Bertrand competition is more intense than Cournot competition, Bertrand competitors react more aggressively to changes in their demand stemming from regulated output reductions. As a consequence, more intense competition relaxes the condition for allowing the merger.

Private information of the merged firm about the realization of post-merger cost synergies strengthens this result. As it is well established in the incentive regulation literature (e.g., Baron and Myerson 1982), a regulator finds it optimal to tolerate an allocative loss from the downward output distortion for the inefficient firm in order to limit the (socially costly) informational rents appropriated by the efficient firm. The prompter reaction of Bertrand competitors to reductions in the regulated output with respect to Cournot competitors alleviates the allocative costs of downward regulated output distortions and softens the regulator's incentive problem.

Afterwards, we show that the optimal merger policy can be crucially affected by the regulated

\footnotetext{
${ }^{4}$ We refer to Section 3 for a discussion about the possibility of efficiency losses.
} 
firms' participation in a competitive segment of the market. In the energy, telecommunications and transportation sectors, regulated utilities may have affiliates in the liberalized part of the market where they operate. While the intensity of Bertrand competition erodes firms' profits and therefore makes the regulated firms' diversification into the unregulated segment inconsequential, things are different under Cournot competition. In particular, when the regulated and unregulated goods are complements, competitive profits can discipline the merged firm's strategic behavior. The efficient merged firm has a weaker incentive to claim to be inefficient since a lower regulated quantity due to cost misrepresentation reduces the demand and the profits in the unregulated segment. The regulated firm's internalization of competitive profits alleviates the regulator's incentive problem and relaxes merger policy. Therefore, if regulated firms diversify into competitive segments of the market that provide complements for the regulated goods, weaker competition can lead to a more lenient merger challenge rule.

To our knowledge, this paper constitutes the first attempt to shed some light on the welfare effects of informational problems about efficiency gains driven by mergers between regulated firms and to provide support for an assessment of the intensity of competition in markets where merging regulated firms interact with unregulated suppliers. Despite the stylized formulation for expositional purposes, with explicit functions and binomial asymmetric information about efficiency gains, the principles underlying our results are fairly general. Our analysis may therefore stimulate the theoretical and practical debate on antitrust and regulation policies.

\section{Related literature}

The emphasis on efficiency gains in merger reviews in unregulated markets traces back to the seminal paper of Williamson (1968), which investigates the welfare trade-off between market power and efficiency gains generated by a merger.

Our work is related to two main strands of the merger literature. The first strand explores the role of pre-merger uncertainty and post-merger private information about efficiency gains. Choné and Linnemer (2008) examine the welfare effects of uncertainty according to the curvature of the social objective function but ignore the presence of asymmetric information after the merger. Closer to our work is the paper of Amir et al. (2009), which analyzes the merger performance when efficiency gains are uncertain before the merger and the merging firms privately observe their realization after the merger. The authors show that a bilateral merger is profitable if non-merging firms believe with a sufficiently high probability that the merger will engender large efficiency gains, even though none actually realize. A further relevant contribution for our purposes is Hamada (2012), which demonstrates that, as the variance of uncertainty about synergies grows, mergers generate larger expected profits and improve expected consumer surplus. Calzolari and Scarpa (2011) explore the welfare effects of allowing a firm that operates in regulated and competitive markets to combine its assets, which creates privately known economies of scope. Contrary to these papers, we examine mergers between regulated firms.

The second strand of literature which is relevant for our purposes investigates the optimal institutional design of regulated industries. We refer to Armstrong and Sappington (2007) for a review on optimal regulation. In a setting with complementary products and private cost information, Baron and Besanko (1992) and Gilbert and Riordan (1995) show that allowing a 
single firm to integrate production improves social welfare through a reduction in informational rents. Iossa (1999) finds that (dis)integrated production tends to be preferred with substitutes (complements) when asymmetric information concerns consumer demand. Contrary to these contributions which ignore technological economies of scope and assume that markets are entirely regulated, we explore the role of uncertainty and asymmetric information about efficiency gains in an industry where regulated and unregulated firms interact.

The rest of the paper is organized as follows. Section 3 sets out the formal model. Section 4 derives the outcome in the absence of a merger. Section 5 considers the benchmark case of full information about post-merger costs. Section 6 characterizes the optimal merger policy under uncertainty and asymmetric information. Section 7 derives the optimal merger policy when regulated firms diversify into a competitive segment of the market. Section 8 discusses some assumptions of the model. Section 9 concludes and provides some implications for antitrust and regulation policies. All formal proofs are collected in the Appendix.

\section{The model}

Setting We wish to investigate the welfare implications of a merger between two regulated firms which operate in two separate markets, for instance two different regions of a country. Each regulated firm interacts with unregulated suppliers since regulated and unregulated goods exhibit some degree of product differentiation.

Following Singh and Vives (1984), consumer surplus gross of the payments to the firms in each market $i=1,2$ is specified as

$$
U_{i}=\alpha q_{i r}+\alpha q_{i u}-\frac{1}{2}\left(q_{i r}^{2}+q_{i u}^{2}+2 \gamma q_{i r} q_{i u}\right),
$$

where $q_{i r}$ and $q_{i u}$ denote the quantities for the regulated and unregulated goods in market $i$. Moreover, $\alpha$ is a positive parameter, and $\gamma \in(-1,1)$ captures the degree of product differentiation between regulated and unregulated goods. If $\gamma>(<) 0$, goods are substitutes (complements). To make our analysis more transparent, and without affecting our qualitative results, we assume that the two markets are symmetric. This reflects the idea that mergers in regulated industries usually involve local natural monopolies which provide the same service (e.g., energy, telecommunications, transportation) but they operate in different regions and face the same competitive segment in each region. ${ }^{5}$

The profit of regulated firm $i=1,2$ in the absence of a merger is

$$
\pi_{i r}=T_{i r}-c q_{i r},
$$

where $T_{i r}$ is a transfer payment to the firm via the regulatory process (see below) and $c$ is the (constant) marginal cost of production. ${ }^{6}$

If the two regulated firms merge, we have a single regulated entity, whose profit becomes

$$
\pi_{r}=T_{r}-C\left(q_{1 r}, q_{2 r} ; \theta\right),
$$

\footnotetext{
${ }^{5}$ In line with the main literature, we abstract from an analysis of the optimal degree of (de)regulation.

${ }^{6}$ Nothing substantial would change with non-linear, different marginal costs.
} 
where $T_{r}$ is a transfer payment to the firm, and $C\left(q_{1 r}, q_{2 r} ; \theta\right)=c q_{1 r}+c q_{2 r}-\theta q_{1 r} q_{2 r}$ represents the total cost of production after the merger. This cost function captures in a simple and natural manner the presence of interdependent costs. ${ }^{7}$ If $\theta=-\frac{\partial^{2} C}{\partial q_{i r} \partial q_{j r}}>(<) 0, i, j=1,2$, $i \neq j$, joint production generates efficiency gains (losses), or (dis)economies of scope, since a larger output for one product reduces (increases) the marginal cost of the other product. Following Farrell and Shapiro (2001, pp. 692-693), we interpret efficiency gains as mergerspecific synergies obtained through the "intimate integration of the parties' unique, hard-totrade assets". ${ }^{8}$ Before the merger, the magnitude of cost synergies is uncertain. It is common knowledge that with probability $\nu \in(0,1)$ the merger entails efficiency gains $\theta_{h}>0$. Following the main literature about uncertain efficiency gains (e.g., Amir et al. 2009), this probability can be thought of as the common belief about the merged firm's ability to achieve the posited efficiency gains, given the information available about the case and possibly all previously treated similar cases. After the merger, the merged firm privately learns the realization of cost synergies. With complementary probability $1-\nu$, the merger results in efficiency losses $\theta_{l}<0$, where $\Delta \theta \equiv \theta_{h}-\theta_{l}>0$. Integrating production may entail higher costs, caused, for instance, by clashes between corporate cultures and difficulties in melding two different managerial and production systems. In the largest cross-national study on mergers over the period 1981-1998, Gugler et al. (2003) conclude that only $29 \%$ of all mergers created efficiency gains. In regulated industries such as electricity, railways and water, empirical investigations report that mergers may entail efficiency losses (e.g., Bitzan and Wilson 2007; Kwoka and Pollitt 2010; Torres and Morrison Paul 2006). In the theoretical literature, the presence of efficiency losses is modelled in some recent contributions (e.g., Choné and Linnemer 2008; Hamada 2012).

Cost synergies constitute the only parameter of private information in our model. This allows us to focus on the informational effects of the merger and makes our analysis more transparent. Remarkably, this formulation is consistent with the common idea that a regulator can (at least to some extent) extract the private information of monopolists operating in different regions by implementing yardstick competition. After the merger, this becomes clearly more difficult, and the new entity is in a better position to manipulate its costs. ${ }^{9}$

In the unregulated segment of each market, two firms $s=1,2$ provide a homogeneous good and obtain profits $\pi^{i s}=p_{i s} q_{i s}-c q_{i s}$, where $\sum_{s=1}^{2} q_{i s} \equiv q_{i u} .{ }^{10}$ The unregulated firms engage either in Bertrand (price) competition or in Cournot (quantity) competition. The difference between these two standard forms of competition captures in a simple and tractable manner the intensity or toughness of product market competition. ${ }^{11}$ Since efficiency gains from the merger must be merger-specific, they do not affect the competitive firms' costs.

\footnotetext{
${ }^{7}$ See, e.g., Motta (2004, Ch. 8) and Calzolari and Scarpa $(2009,2011)$ for the use of this cost specification.

${ }^{8}$ We ignore savings on fixed costs which follow from a reduction in administrative and personnel costs after the merger, since they do not affect our qualitative results. These synergies are viewed with skepticism by antitrust authorities, because they typically stem from a mere output reorganization that could be achieved without the merger (e.g., Motta 2004, Ch. 5).

${ }^{9}$ We refer to Section 8.1 for further discussion about this point.

${ }^{10}$ Our qualitative results carry over if we consider product differentiation (and possibly different costs) even within the competitive segment of the market. Our analysis can also be generalized to the case of more than two firms.

${ }^{11}$ In Section 9, we provide practical examples where Bertrand or Cournot competition tends to prevail.
} 
Using (1), the aggregate net consumer surplus in the two markets is given by

$$
C S=U_{1}+U_{2}-\left(T_{1 r}+T_{2 r}\right)-\sum_{s=1}^{2} p_{1 s} q_{1 s}-\sum_{s=1}^{2} p_{2 s} q_{2 s}
$$

with $T_{1 r}+T_{2 r}$ being replaced by $T_{r}$ in case of merger. A regulator is charged with maximizing welfare in (4) when designing the regulatory policy. ${ }^{12}$ In the absence of the merger, the regulator offers a contract $\left\{T_{i r}, q_{i r}\right\}$ to regulated firm $i=1,2$. If the merger occurs, the contract offered to the regulated merged entity is $\left\{T_{r}, q_{1 r}, q_{2 r}\right\}$. It is worth noting that the regulatory contract specifies a transfer and a quantity for each good, irrespective of the mode of competition in the unregulated segment. Using standard techniques, our results carry over if we allow for regulation of prices for regulated goods. ${ }^{13}$

The welfare standard in (4) is also relevant to merger policy. This reflects the common perception that, at least in Europe and in the US, antitrust authorities focus on consumer surplus in merger investigations (e.g., Motta 2004, Ch. 1). ${ }^{14}$

Timing We consider the following sequence of events.

(I) The regulator decides whether to allow the merger between regulated firms or not.

(II) If the merger is not allowed, the regulator makes a take-it-or-leave-it offer of a regulatory policy to each regulated firm, which can either accept or reject the offer. If merger is allowed, the merged entity privately learns the realization of its cost type $\theta \in\left\{\theta_{h}, \theta_{l}\right\}$. Afterwards, the regulator makes a take-it-or-leave-it offer of a regulatory policy to the merged entity, which can either accept or reject the offer (the reservation utility is normalized to zero).

(III) If the regulatory offer(s) is (are) accepted, regulation is implemented.

(IV) Competition in the unregulated segment takes place.

In summary, our model is a two-stage game. After deciding on the merger, in the first stage the regulator determines the regulatory policy. In the second stage, competition occurs in the unregulated segment. We solve this game by backward induction.

Some remarks are in order at this point. We do not distinguish between the antitrust authority and the regulatory agency, since in practice they usually have concurrent jurisdiction over merger reviews in regulated industries and cooperate to reach a final decision. ${ }^{15}$ Moreover, we consider a single regulator charged with controlling both markets. In practice, however, different regulators are sometimes established, one for each market, and miscoordination problems might occur after the merger. While no externalities arise on the demand side since consumers are in different markets, the cost function in (3) of the merged firm is nonseparable in the two regulated outputs and therefore assigning each regulator the control of a part of the merged firm's profits cannot be done in an unambiguous way. To cope with regulatory miscoordination

\footnotetext{
${ }^{12}$ Without loss of generality, we neglect the social cost of collecting funds through distortionary taxation to finance regulated production. This increases unnecessarily further the cost of transfers in the welfare function and does not affect our qualitative conclusions (Armstrong and Sappington 2007). In the same vein, our qualitative results go through if we allow for a weight (lower than 1) attached to profits in the welfare standard in (4).

${ }^{13}$ Computations are available upon request.

${ }^{14}$ Theoretical foundations can be found in Neven and Röller (2005).

${ }^{15}$ Miscoordination between the antitrust authority and the regulator would introduce additional issues which are outside the scope of this paper.
} 
problems, in practice a regulator with larger jurisdiction is usually involved, such as the Federal Energy Regulatory Commission (FERC) for mergers and acquisitions of energy utilities in the US. In other cases, active cooperation is promoted between regulators. To focus on the welfare effects of informational problems about efficiency gains, we abstract from the additional issues arising from potential miscoordination between regulators.

In line with relevant contributions to the merger literature (e.g., Amir et al. 2009; Choné and Linnemer 2008; Hamada 2012), the realization of cost synergies occurs after the merger. As discussed in the introduction, practitioners acknowledge that cost synergies cannot be precisely quantified before a merger has been consummated. Moreover, the implementation of regulatory contracting naturally precedes the competition stage. This reflects the complexity of regulatory rules and procedures, which are more difficult to alter than market decisions.

Finally, we take as exogenously given the merger decision of the regulated firms. Section 8.2 is devoted to a discussion of the firms' incentives to merge.

\section{The case where the merger is not allowed}

Let $q_{i u}^{k}\left(q_{i r}\right), k=b, c$, be the second-stage total output in the unregulated segment of market $i$ under Bertrand or Cournot competition and $p_{i u}^{k}($.$) the corresponding price. When the merger$ is not allowed, the two markets are fully separated, and therefore the regulator's problem of maximizing welfare in (4) can be split into two different maximization problems.

Replacing $T_{i r}$ with $\pi_{i r}$ from regulated firm $i$ 's profit function in (2) and using the secondstage competition outcome, in the first stage the regulator's objective to maximize welfare in market $i$ can be written in the following way

$$
\max _{q_{i r}, \pi_{i r}}(\alpha-c) q_{i r}+\alpha q_{i u}^{k}-\frac{1}{2} q_{i r}^{2}-\frac{1}{2}\left(q_{i u}^{k}\right)^{2}-\gamma q_{i r} q_{i u}-p_{i u}^{k} q_{i u}^{k}-\pi_{i r} \quad \text { s.t. } \pi_{i r} \geq 0,
$$

where the constraint ensures that the regulated firm in market $i$ accepts the regulatory contract.

The following lemma formalizes the main results when the merger is not permitted.

Lemma 1 If the merger is not allowed, under Bertrand competition in the unregulated segment, the outputs in market $i$ are

$$
q_{i r}^{b}=q_{i u}^{b}=\frac{\alpha-c}{1+\gamma} .
$$

Under Cournot competition in the unregulated segment, the outputs in market $i$ are

$$
q_{i r}^{c}=\frac{9-4 \gamma}{9-4 \gamma^{2}}(\alpha-c) ; \quad q_{i u}^{c}=\frac{6(1-\gamma)}{9-4 \gamma^{2}}(\alpha-c) .
$$

Since Bertrand is more intense than Cournot competition, unregulated output is higher when firms compete à la Bertrand. To mitigate the welfare loss from Cournot competition, the quantity for each substitutable (complementary) regulated good increases (decreases). 


\section{Full information}

We now examine the benchmark case where the magnitude of efficiency gains (losses) $\theta \in\left\{\theta_{h}, \theta_{l}\right\}$ is common knowledge before the merger takes place. When the merger is allowed, after replacing $T_{r}$ with $\pi_{r}$ from the merged firm's profit function in (3) and using the second-stage competition outcome, the regulator's problem of maximizing welfare in (4) becomes

$$
\max _{q_{i r}, \pi_{r}} \sum_{s=1}^{2}\left[(\alpha-c) q_{i r}+\alpha q_{i u}^{k}-\frac{1}{2} q_{i r}^{2}-\frac{1}{2}\left(q_{i u}^{k}\right)^{2}-\gamma q_{i r} q_{i u}^{k}-p_{i u}^{k} q_{i u}^{k}\right]+\theta q_{1 r} q_{2 r}-\pi_{r} \quad \text { s.t. } \quad \pi_{r} \geq 0
$$

where the constraint guarantees that the merged firm accepts the regulatory contract.

We summarize the main results of the maximization program in the following lemma.

Lemma 2 Suppose that there is full information about $\theta \in\left\{\theta_{h}, \theta_{l}\right\}$ before the merger. Then, if the merger is allowed, under Bertrand competition in the unregulated segment, the outputs in market $i$ are

$$
q_{i r}^{m b}=\frac{1-\gamma}{1-\gamma^{2}-\theta}(\alpha-c) ; \quad q_{i u}^{m b}=\frac{1-\gamma-\theta}{1-\gamma^{2}-\theta}(\alpha-c) .
$$

Under Cournot competition in the unregulated segment, the outputs in market $i$ are

$$
q_{i r}^{m c}=\frac{9-4 \gamma}{9-4 \gamma^{2}-9 \theta}(\alpha-c) ; \quad q_{i u}^{m c}=\frac{6(1-\gamma-\theta)}{9-4 \gamma^{2}-9 \theta}(\alpha-c) .
$$

Lemmas 1 and 2 indicate that a merger leads to a larger regulated production if and only if it creates efficiency gains $\left(\theta=\theta_{h}>0\right)$. If goods are substitutes, the higher (lower) regulated output due to efficiency gains (losses) entails a reduction (raise) in the unregulated quantity. The opposite clearly holds when goods are complements.

We can now state the following result.

Lemma 3 With full information about $\theta \in\left\{\theta_{h}, \theta_{l}\right\}$, the merger is welfare enhancing if and only if $\theta=\theta_{h}$, irrespective of the mode of competition in the unregulated segment.

In the absence of informational problems about post-merger costs, the merger desirability only depends on the magnitude of these costs. A merger should be approved if and only if it engenders efficiency gains, and the mode of competition prevailing in the unregulated segment is therefore inconsequential.

\section{Unknown efficiencies}

Now, we show that the natural result in Lemma 3 does not holds when post-merger costs are uncertain before the merger and their realization becomes private information of the merged firm.

\subsection{Uncertainty}

In order to better appreciate the impact of uncertainty and asymmetric information, we first consider the case where efficiency gains (losses) are uncertain before the merger occurs and 
become common knowledge after the merger. Since the regulator is fully informed about the post-merger costs when designing the regulatory policy, the results in Lemma 2 still apply. However, the regulator's merger decision now takes place before costs realize.

The following proposition derives the optimal merger policy under uncertain efficiency gains.

Proposition 1 Suppose that $\theta \in\left\{\theta_{h}, \theta_{l}\right\}$ is uncertain before the merger and becomes common knowledge after the merger. Then, under Bertrand competition in the unregulated segment, the merger is ex ante welfare enhancing if and only if

$$
\nu>-\frac{1-\gamma^{2}-\theta_{h}}{\left(1-\gamma^{2}\right) \Delta \theta} \theta_{l} \equiv \nu^{b} \in(0,1) .
$$

Under Cournot competition in the unregulated segment, the merger is ex ante welfare enhancing if and only if

$$
\nu>-\frac{9-4 \gamma^{2}-9 \theta_{h}}{\left(9-4 \gamma^{2}\right) \Delta \theta} \theta_{l} \equiv \nu^{c} \in(0,1) .
$$

Proposition 1 reveals the natural result that, when the magnitude of costs generated by the merger is uncertain, the merger should be approved only if the probability of efficiency gains is relatively high. More relevantly, conditions (5) and (6) show that, in the presence of uncertainty, the form of competition prevailing in the unregulated part of the market affects the optimal merger policy.

This leads to the following result.

Proposition 2 We have $\nu^{c} \geq \nu^{b}$, where the equality holds if and only if $\gamma=0$.

Proposition 2 shows that Bertrand competition in the unregulated part of the market relaxes the condition for allowing the merger. As the regulator's merger decision is made under uncertainty about cost realization, an ex ante welfare-enhancing merger may eventually result in efficiency losses, namely, higher post-merger costs, which lead to lower regulated production. Since Bertrand is more intense than Cournot competition, Bertrand suppliers react more aggressively to reductions in regulated production. This alleviates the welfare losses from more inefficient post-merger regulated activities. As a consequence, more severe competition in the unregulated segment of the market allows the regulator to establish a merger challenge rule which is more lenient with the merging firms.

\subsection{Uncertainty and asymmetric information}

We now consider the case where cost synergies are uncertain before the merger and privately observed by the merged firm after the merger. Invoking the revelation principle (e.g., Myerson 1979), the regulator can restrict attention to a direct incentive compatible contract menu $\left\{\left(T_{r h}, q_{1 r h}, q_{2 r h}\right),\left(T_{r l}, q_{1 r l}, q_{2 r l}\right)\right\}$ that induces the merged firm to truthfully reveal its cost type $\theta \in\left\{\theta_{h}, \theta_{l}\right\}$. Using the merged firm's profit in (3), in addition to the participation constraints 
$\pi_{r h} \geq 0$ and $\pi_{r l} \geq 0$, the following incentive compatibility constraints must be fulfilled

$$
\begin{aligned}
\pi_{r h} & =T_{r h}-c q_{1 r h}-c q_{2 r h}+\theta_{h} q_{1 r h} q_{2 r h} \\
& \geq T_{r l}-c q_{1 r l}-c q_{2 r l}+\theta_{h} q_{1 r l} q_{2 r l} \\
& =\pi_{r l}+\Delta \theta q_{1 r l} q_{2 r l} \\
& \\
\pi_{r l} & =T_{r l}-c q_{1 r l}-c q_{2 r l}+\theta_{l} q_{1 r l} q_{2 r l} \\
& \geq T_{r h}-c q_{1 r h}-c q_{2 r h}+\theta_{l} q_{1 r h} q_{2 r h} \\
& =\pi_{r h}-\Delta \theta q_{1 r h} q_{2 r h} .
\end{aligned}
$$

Conditions (7) and (8) ensure that the merged firm does not benefit from misreporting its private information.

Following standard techniques, we restrict attention to the incentive constraint (7) for the efficient firm and the participation constraint $\pi_{r l} \geq 0$ for the inefficient firm, which are binding at the optimal contract. ${ }^{16}$ Substituting these binding constraints and the second-stage competition outcome into (4), the regulator's maximization problem can be written in the following way

$$
\begin{aligned}
& \max _{q_{i r h}, q_{i r l}} \nu\left\{\sum_{i=1}^{2} q_{i s}\left[(\alpha-c) q_{i r h}+\alpha q_{i u h}^{k}-\frac{1}{2} q_{i r h}^{2}-\frac{1}{2}\left(q_{i u h}^{k}\right)^{2}-\gamma q_{i r h} q_{i u h}^{k}-p_{i u h}^{k} q_{i u h}^{k}\right]\right. \\
& \left.+\theta_{h} q_{1 r h} q_{2 r h}-\Delta \theta q_{1 r l} q_{2 r l}\right\}+(1-\nu) \\
& \times\left\{\sum_{i=1}^{2}\left[(\alpha-c) q_{i r l}+\alpha q_{i u l}^{k}-\frac{1}{2} q_{i r l}^{2}-\frac{1}{2}\left(q_{i u l}^{k}\right)^{2}-\gamma q_{i r l} q_{i u l}^{k}-p_{i u l}^{k} q_{i u l}^{k}\right]+\theta_{l} q_{1 r l} q_{2 r l}\right\},
\end{aligned}
$$

where the two expressions in curly brackets represent the welfare generated with the efficient and inefficient firm, respectively. After defining

$$
\phi(\nu) \equiv \frac{\nu}{1-\nu}
$$

we are able to formalize the main results of the maximization program in the following lemma.

Lemma 4 Suppose that $\theta \in\left\{\theta_{h}, \theta_{l}\right\}$ is uncertain before the merger and becomes private information of the merged firm after the merger. If the merger is allowed, under Bertrand competition in the unregulated segment, the outputs in market $i$ are

$$
\begin{aligned}
\widetilde{q}_{i r h}^{m b} & =\frac{1-\gamma}{1-\gamma^{2}-\theta_{h}}(\alpha-c) ; \quad \widetilde{q}_{i r l}^{m b}=\frac{1-\gamma}{1-\gamma^{2}-\theta_{l}+\Delta \theta \phi}(\alpha-c) \\
\widetilde{q}_{i u h}^{m b} & =\frac{1-\gamma-\theta_{h}}{1-\gamma^{2}-\theta_{h}}(\alpha-c) ; \quad \widetilde{q}_{i u l}^{m b}=\frac{1-\gamma-\theta_{l}+\Delta \theta \phi}{1-\gamma^{2}-\theta_{l}+\Delta \theta \phi}(\alpha-c) .
\end{aligned}
$$

\footnotetext{
${ }^{16}$ This result follows because, if either constraint were slack, the regulator could offer an alternative contract which reduces the transfer to the merged firm and increases welfare in (4). In the proof of Lemma 4 (provided in the Appendix), we show that the two remaining constraints, namely, the participation constraint for the efficient firm $\pi_{r h} \geq 0$ and the incentive constraint (8) for the inefficient firm, are slack in equilibrium.
} 
Under Cournot competition in the unregulated segment, the outputs in market $i$ are

$$
\begin{aligned}
\widetilde{q}_{i r h}^{m c} & =\frac{9-4 \gamma}{9-4 \gamma^{2}-9 \theta_{h}}(\alpha-c) ; & \widetilde{q}_{i r l}^{m c}=\frac{9-4 \gamma}{9-4 \gamma^{2}-9 \theta_{l}+9 \Delta \theta \phi}(\alpha-c) \\
\widetilde{q}_{i u h}^{m c} & =\frac{6\left(1-\gamma-\theta_{h}\right)}{9-4 \gamma^{2}-9 \theta_{h}}(\alpha-c) ; & \widetilde{q}_{i u l}^{m c}=\frac{6\left(1-\gamma-\theta_{l}+\Delta \theta \phi\right)}{9-4 \gamma^{2}-9 \theta_{l}+9 \Delta \theta \phi}(\alpha-c) .
\end{aligned}
$$

A comparison of the results in Lemmas 2 and 4 reveals the familiar trade-off between allocative efficiency and the firm's rent extraction in the presence of asymmetric information (e.g., Baron and Myerson 1982). The production of the efficient firm coincides with that under full information ("no distortion at the top" result). However, the regulator finds it optimal to reduce the output of the inefficient firm in order to limit the (socially costly) informational rents in (7) to the efficient firm. The quantities for both goods of the inefficient merged firm are distorted downward, since asymmetric information concerns the costs of joint production.

These regulatory distortions affect in a predictable way the production in the unregulated segment of each market. Irrespective of the mode of competition, the substitutability (complementarity) between goods implies that the lower regulated production of the inefficient firm stimulates (dampens) the demand for the unregulated good.

Equipped with the results in Lemma 4, we can characterize the optimal merger policy in the presence of uncertainty and asymmetric information.

Proposition 3 Suppose that $\theta \in\left\{\theta_{h}, \theta_{l}\right\}$ is uncertain before the merger and becomes private information of the merged firm after the merger. Then, under Bertrand competition in the unregulated segment, the merger is ex ante welfare enhancing if and only if

$$
\nu>-\frac{1-\gamma^{2}-\theta_{h}}{\theta_{h}^{2}-\left(1-\gamma^{2}\right) \theta_{l}} \theta_{l} \equiv \widetilde{\nu}^{b} \in\left(\nu^{b}, 1\right) .
$$

Under Cournot competition in the unregulated segment, the merger is ex ante welfare enhancing if and only if

$$
\nu>-\frac{9-4 \gamma^{2}-9 \theta_{h}}{9 \theta_{h}^{2}-\left(9-4 \gamma^{2}\right) \theta_{l}} \theta_{l} \equiv \widetilde{\nu}^{c} \in\left(\nu^{c}, 1\right) .
$$

When efficiency gains are uncertain before the merger and their realization becomes private information of the merged firm, the merger yields a trade-off between the benefits of potential efficiency gains and the social costs of regulatory distortions. The combination of asymmetric information and uncertainty complicates the regulator's informational problem. Therefore, irrespective of the mode of competition, the regulator sets a stricter merger challenge rule.

We are now in a position to state the following result.

Proposition 4 We have $\widetilde{\nu}^{c}-\widetilde{\nu}^{b} \geq \nu^{c}-\nu^{b} \geq 0$, where the equality holds if and only if $\gamma=0$.

As Figure 1 illustrates, asymmetric information strengthens the condition for allowing the merger under Cournot competition to a larger extent than the corresponding condition under Bertrand competition. This increases the sensitivity of merger policy to the intensity of competition in the unregulated segment of the market. The presence of asymmetric information 


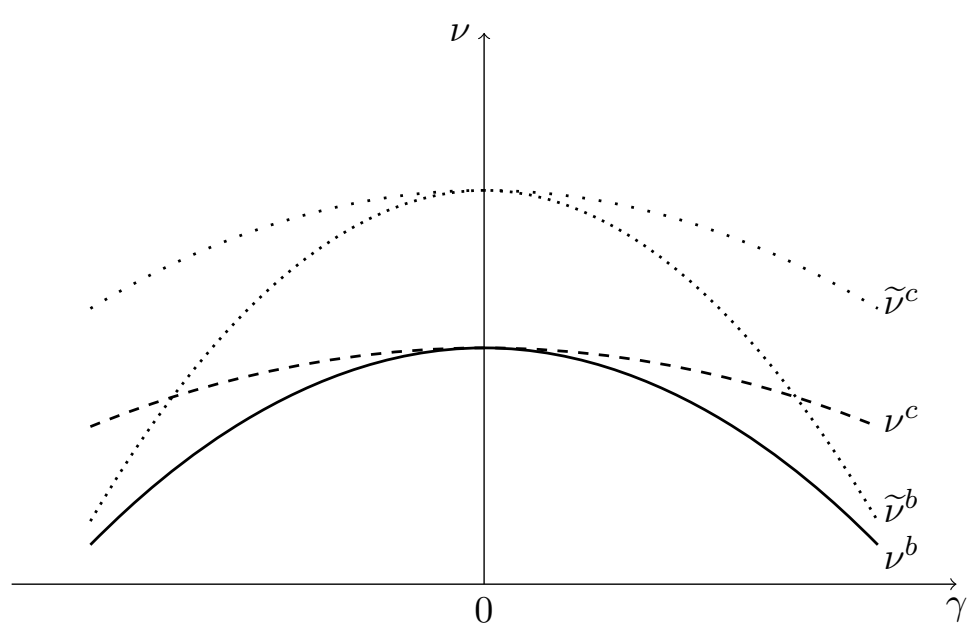

Figure 1: Merger policy

in addition to uncertainty aggravates the regulator's informational problem. We know from Lemma 4 that this translates into a further reduction in the regulated output of the inefficient firm in order to reduce the informational rents appropriated by the efficient firm. The higher intensity of Bertrand competition mitigates the associated welfare losses to a larger extent than Cournot competition. Hence, the combination of pre-merger uncertainty and post-merger asymmetric information about synergies induces the regulator to increase the toughness of the merger challenge rule in response to weaker competition in the unregulated part of the market.

We can see from Figure 1 that the degree of differentiation between regulated and unregulated goods affects the optimal merger policy. A higher demand interdependence results in a more lenient merger policy, irrespective of the mode of competition. This is because the competitive segment can alleviate to a greater extent the allocative losses in the regulated part of market driven by informational problems. In the light of our previous discussion, it does not come entirely as a surprise that this effect is more pronounced under Bertrand than under Cournot competition, since Bertrand competitors respond more efficiently to regulatory distortions. Therefore, if we interpret the degree of substitutability as a measure of the strength of competition between regulated and unregulated firms, we can conclude that more intense competition both among unregulated firms and between regulated and unregulated firms induces a more lenient merger challenge rule.

\section{Diversification into the unregulated segment}

In practice, regulated firms can be active in a competitive part of the market as well. Regulated utilities that provide energy transmission and distribution may engage in competitive retail services. Regulated suppliers of basic local telephone services may also offer long-distance telephone and broadband Internet services at unregulated rates. In this section, we investigate the implications for the design of the optimal merger policy that arise when regulated firms diversify into a competitive segment of the market.

In line with the most common regulatory practices in Europe and in the US, we assume that regulated activities of a firm are legally unbundled from its competitive activities. This entails 
separate accounts for regulated and competitive operations so that provision of each commodity is stand-alone profitable, and the regulator is only allowed to control regulated activities. ${ }^{17} \mathrm{As}$ Vickers (1995, p. 14) suggests, a realistic formulation of the participation constraint requires that, as in the absence of diversification, a firm at least break even in its regulated activities. Moreover, in the literature on legal unbundling (e.g., Cremer and De Donder 2013; Höffler and Kranz 2011; Sibley and Weisman 1998), a regulated firm is entitled to receive the competitive profits but cannot interfere in the operations of the competitive affiliate, which independently maximizes its own profits. In our setting, the maximization of competitive profits follows irrespective of whether the affiliate cares about its own profits or total profits, since regulated profits are entirely determined by the regulatory contract.

For our aims, it is important to recognize that this discussion implies that the results in the absence of a merger in Section 4 remain unchanged, and therefore Lemma 1 still applies. ${ }^{18}$ However, the regulated firm's diversification into the unregulated segment of the market affects the firm's incentive to strategically manipulate its private information about the efficiency gains from the merger, since it internalizes the impact of its behavior on the profits of the competitive affiliate.

When unregulated suppliers engage in Bertrand competition, profits are competed away. Hence, the regulated firm's diversification is inconsequential and our previous results are unaffected. We show that diversification into a Cournot segment leads to results of some interest.

As in the baseline model, we consider two identical competitive firms $s=1,2$ in each market $i=1,2$, which have profits $\pi^{i s}\left(q_{i r}\right)$. Regulated firm $i$ now owns one competitive subsidiary (say, firm 1) in the market where it operates, whose profits are $\pi^{i 1}\left(q_{i r}\right) \cdot{ }^{19}$ Since the subsidiary maximizes its own profits, the outcome in the competition stage is unchanged.

If the merger is allowed, the new regulated entity controls two competitive firms, one in each market. The merged firm cares about the sum of regulated and unregulated profits when manipulating its private information. Formally, the incentive compatibility constraints are given by

$$
\begin{aligned}
\pi_{r h}+\pi^{11}\left(q_{1 r h}\right)+\pi^{21}\left(q_{2 r h}\right) & =T_{r h}-c q_{1 r h}-c q_{2 r h}+\theta_{h} q_{1 r h} q_{2 r h}+\pi^{11}\left(q_{1 r h}\right)+\pi^{21}\left(q_{2 r h}\right) \\
& \geq T_{r l}-c q_{1 r l}-c q_{2 r l}+\theta_{h} q_{1 r l} q_{2 r l}+\pi^{11}\left(q_{1 r l}\right)+\pi^{21}\left(q_{2 r l}\right) \\
& =\pi_{r l}+\Delta \theta q_{1 r l} q_{2 r l}+\pi^{11}\left(q_{1 r l}\right)+\pi^{21}\left(q_{2 r l}\right)
\end{aligned}
$$

\footnotetext{
${ }^{17}$ For instance, the Telecommunications Act of 1996 provides that the US incumbent local exchange carriers can obtain a reasonable profit from regulated activities. Earnings from unregulated activities are not relevant to the definition of a reasonable profit (Sidak and Spulber 1998, Ch. 9).

${ }^{18}$ This conclusion deserves a remark. If goods are complements, the diversified regulated firm is willing to accept the regulatory contract when it obtains non-negative profits from regulated activities. This is not the case under substitutability, since regulated production reduces the demand and the profits in the unregulated segment. In order to induce the regulated firm to accept the regulatory contract, the regulator could prohibit the regulated firm's diversification into the unregulated segment when it rejects a contract which guarantees non-negative regulated profits. If this is not feasible, a further constraint should be introduced, which ensures the firm's participation in the regulatory relationship. It can be shown that this additional constraint does not alter the qualitative comparison between merger challenge rules under Bertrand and Cournot competition, and therefore our main results carry over.

${ }^{19}$ Our qualitative results carry over when only one regulated firm diversifies into the competitive segment. In Section 9, we discuss the case in which one regulated firm expands into the unregulated segment of the market where the other regulated firm operates.
} 


$$
\begin{aligned}
\pi_{r l}+\pi^{11}\left(q_{1 r l}\right)+\pi^{21}\left(q_{2 r l}\right) & =T_{r l}-c q_{1 r l}-c q_{2 r l}+\theta_{l} q_{1 r l} q_{2 r l}+\pi^{11}\left(q_{1 r l}\right)+\pi^{21}\left(q_{2 r l}\right) \\
& \geq T_{r h}-c q_{1 r h}-c q_{2 r h}+\theta_{l} q_{1 r h} q_{2 r h}+\pi^{11}\left(q_{1 r h}\right)+\pi^{21}\left(q_{2 r h}\right) \\
& =\pi_{r h}-\Delta \theta q_{1 r h} q_{2 r h}+\pi^{11}\left(q_{1 r h}\right)+\pi^{21}\left(q_{2 r h}\right) .
\end{aligned}
$$

From the second-stage Cournot competition the profits of the subsidiary in market $i$ are $\pi^{i 1}\left(q_{i r}\right)=\frac{\left(\alpha-c-\gamma q_{i r}\right)^{2}}{9}, i=1,2$. Then, the incentive constraints can be rewritten after some manipulation in the following way

$$
\begin{aligned}
& \pi_{r h} \geq \pi_{r l}+\Delta \theta q_{1 r l} q_{2 r l}+\frac{\gamma}{9} \sum i=1^{2}\left(2 \alpha-2 c-\gamma q_{i r h}-\gamma q_{i r l}\right)\left(q_{i r h}-q_{i r l}\right) \\
& \pi_{r l} \geq \pi_{r h}-\Delta \theta q_{1 r h} q_{2 r h}+\frac{\gamma}{9} \sum i=1^{2}\left(2 \alpha-2 c-\gamma q_{i r h}-\gamma q_{i r l}\right)\left(q_{i r l}-q_{i r h}\right) .
\end{aligned}
$$

Adding (12) and (13) yields

$$
q_{1 r h} q_{2 r h} \geq q_{1 r l} q_{2 r l} .
$$

As in Section 6, we restrict attention to the incentive constraint (12) for the efficient firm and the participation constraint $\pi_{r l} \geq 0$ for the inefficient firm, which are therefore binding at the optimal contract. This approach is justified if condition (14) holds, which constitutes a necessary condition for incentive compatibility.

Substituting the binding constraints and the second-stage Cournot outcome into (4), the regulator's maximization problem is given by

$$
\begin{aligned}
& \max _{q_{i r h}, q_{i r l}} \nu\left\{\sum i=1^{2}\left[(\alpha-c) q_{i r h}+\alpha q_{i u h}^{k}-\frac{1}{2} q_{i r h}^{2}-\frac{1}{2}\left(q_{i u h}^{k}\right)^{2}-\gamma q_{i r h} q_{i u h}^{k}-p_{i u h}^{k} q_{i u h}^{k}\right]\right. \\
& \left.+\theta_{h} q_{1 r h} q_{2 r h}-\Delta \theta q_{1 r l} q_{2 r l}-\frac{\gamma}{9} \sum i=1^{2}\left(2 \alpha-2 c-\gamma q_{i r h}-\gamma q_{i r l}\right)\left(q_{i r h}-q_{i r l}\right)\right\}+(1-\nu) \\
& \times\left\{\sum i=1^{2}\left[(\alpha-c) q_{i r l}+\alpha q_{i u l}^{k}-\frac{1}{2} q_{i r l}^{2}-\frac{1}{2}\left(q_{i u l}^{k}\right)^{2}-\gamma q_{i r l} q_{i u l}^{k}-p_{i u l}^{k} q_{i u l}^{k}\right]+\theta_{l} q_{1 r l} q_{2 r l}\right\} .
\end{aligned}
$$

The main results of the maximization program are summarized in the following lemma.

Lemma 5 Suppose that $\theta \in\left\{\theta_{h}, \theta_{l}\right\}$ is uncertain before the merger and becomes private information of the merged firm after the merger. Moreover, suppose that the regulated firms diversify into the unregulated segment, where competition takes place à la Cournot. Then, if the merger is allowed, the outputs in market $i$ are

$$
\begin{aligned}
& \widetilde{q}_{i r h}^{m c d}=\frac{3-2 \gamma}{3-2 \gamma^{2}-3 \theta_{h}}(\alpha-c) ; \quad \widetilde{q}_{i r l}^{m c d}=\frac{9-4 \gamma+2 \gamma \phi}{9-4 \gamma^{2}-9 \theta_{l}+\left(2 \gamma^{2}+9 \Delta \theta\right) \phi}(\alpha-c) \\
& \widetilde{q}_{i u h}^{m c d}=\frac{6\left(1-\gamma-\theta_{h}\right)}{9-6 \gamma^{2}-9 \theta_{h}}(\alpha-c) ; \quad \widetilde{q}_{i u l}^{m c d}=\frac{6\left(1-\gamma-\theta_{l}+\Delta \theta \phi\right)}{9-4 \gamma^{2}-9 \theta_{l}+\left(2 \gamma^{2}+9 \Delta \theta\right) \phi}(\alpha-c) .
\end{aligned}
$$

The diversification into a Cournot segment crucially affects the regulatory policy designed for the merged firm. When goods are substitutes, the efficient merged firm has a stronger incentive to claim to be inefficient, since a lower regulated quantity due to cost misrepresentation increases the demand and the profits in the unregulated segment. In fact, the incentive constraint (12) 
is more severe than the constraint (7). As Lemmas 4 and 5 reveal, the regulator reduces the quantity of the efficient firm, $\widetilde{q}_{i r h}^{m c d}<\widetilde{q}_{i r h}^{m c}$, and increases the quantity of the inefficient firm, $\widetilde{q}_{i r l}^{m c d}>\widetilde{q}_{i r l}^{m c}$, in order to curb the informational rents in (12).

The reverse occurs when goods are complements. A lower regulated quantity due to cost misrepresentation now reduces the demand and profits in the unregulated segment, which mitigates the regulator's incentive problem. As Lemmas 4 and 5 indicate, the regulator prefers to increase the wedge between the regulated output of the efficient firm and that of the inefficient firm, namely, $\widetilde{q}_{i r h}^{m c d}>\widetilde{q}_{i r h}^{m c}$ and $\widetilde{q}_{i r l}^{m c d}<\widetilde{q}_{i r l}^{m c}$, since this allows a higher rent extraction.

Equipped with the results in Lemma 5 and using (9), we can now formalize the merger policy when the regulated firms expand into the unregulated segment.

Proposition 5 Suppose that $\theta \in\left\{\theta_{h}, \theta_{l}\right\}$ is uncertain before the merger and becomes private information of the merged firm after the merger. Moreover, suppose that the regulated firms diversify into the unregulated segment, where competition takes place à la Cournot. Then,

(i) when goods are substitutes, i.e., $\gamma \geq 0$, there exists a threshold $\theta_{h}^{*}(\gamma) \geq 0$ (where $\theta_{h}^{*}=0$ if and only if $\gamma=0$ ) such that for $\theta_{h} \leq \theta_{h}^{*}$ the merger is never ex ante welfare enhancing. For $\theta_{h}>\theta_{h}^{*}$ the merger is ex ante welfare enhancing if and only if $\phi(\nu)>\widetilde{\phi}_{d}^{c}$, where $\widetilde{\phi}_{d}^{c}>0$ is given by

$$
\frac{-(9-4 \gamma)^{2}\left(3-2 \gamma^{2}-3 \theta_{h}\right) \theta_{l}}{\Delta \theta\left[2 \gamma\left(57 \gamma-8 \gamma^{3}-54\right)+3 \theta_{h}(9-4 \gamma)^{2}\right]+2 \gamma^{2}\left[6(1-\gamma)^{2}+\theta_{h}\left(21+8 \gamma^{2}-24 \gamma\right)\right]}
$$

(ii) when goods are complements, i.e., $\gamma<0$, the merger is ex ante welfare enhancing if and only if $\phi(\nu)>\widetilde{\phi}_{d}^{c}$.

We know from the discussion following Lemma 5 that the regulated firms' diversification into a competitive segment which provides substitutes for the regulated goods complicates the regulator's incentive problem. As Proposition 5 reveals, when the magnitude of efficiency gains the merger may generate is small enough, the regulator prefers to block the merger. Otherwise, the merger is allowed if the probability of efficiency gains is relatively high.

In order to investigate the impact of diversification on the optimal merger policy, we rewrite the merger conditions (10) and (11) as follows

$$
\begin{gathered}
\phi(\nu)>-\frac{1-\gamma^{2}-\theta_{h}}{\theta_{h} \Delta \theta} \theta_{l} \equiv \widetilde{\phi}^{b}=\widetilde{\phi}_{d}^{b} \\
\phi(\nu)>-\frac{9-4 \gamma^{2}-9 \theta_{h}}{9 \theta_{h} \Delta \theta} \theta_{l} \equiv \widetilde{\phi}^{c} .
\end{gathered}
$$

We can now state the following conclusion.

Proposition 6 Suppose that $\theta \in\left\{\theta_{h}, \theta_{l}\right\}$ is uncertain before the merger and becomes private information of the merged firm after the merger. Then,

(i) when goods are substitutes, i.e., $\gamma \geq 0$, we have $\widetilde{\phi}_{d}^{c} \geq \widetilde{\phi}^{c} \geq \widetilde{\phi}^{b}$, where the equality holds if and only if $\gamma=0$;

(ii) when goods are complements, i.e., $\gamma<0$, we have $\widetilde{\phi}_{d}^{c}<\widetilde{\phi}^{c}$. Moreover, there exists a threshold $\widetilde{\theta}_{h}(\gamma)>0$, with $\frac{\partial \widetilde{\theta}_{h}}{\partial \gamma}>0$, such that for $\theta_{h}<\widetilde{\theta}_{h}$ we have $\widetilde{\phi}^{b}>\widetilde{\phi}_{d}^{c}$. 


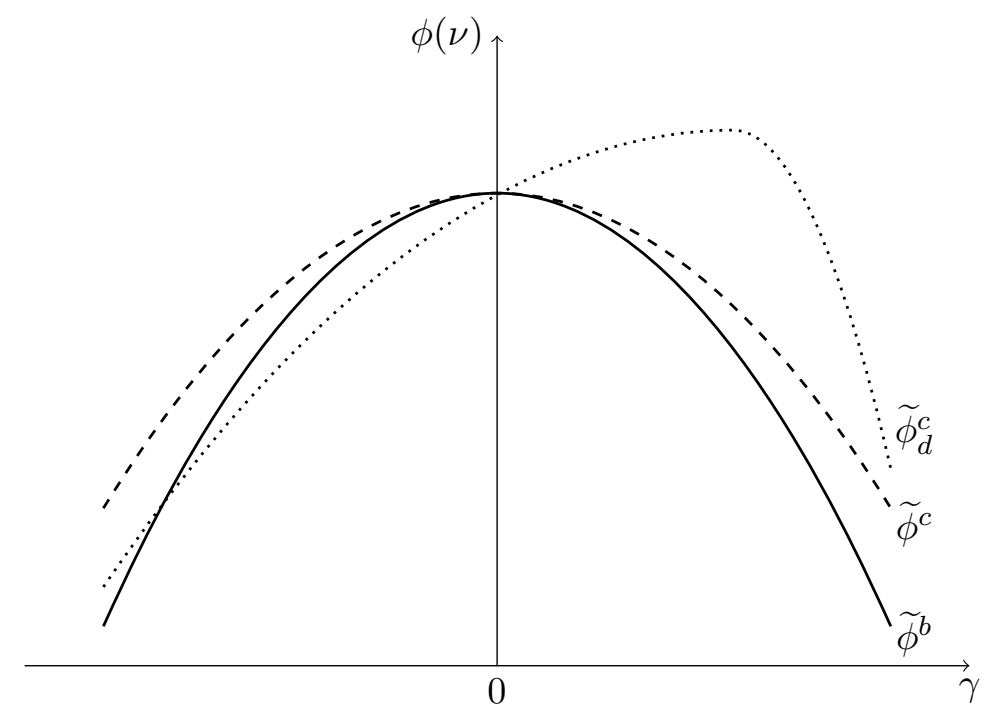

Figure 2: Merger policy under diversification

As Figure 2 illustrates, when goods are substitutes the regulated firms' diversification into the Cournot segment induces the regulator to establish a stricter merger challenge rule. This is a consequence of the firm's stronger incentive to manipulate its private information after the merger.

When goods are complements, different forces are at work. The regulated firm's diversification under Cournot competition alleviates the regulator's incentive problem, which relaxes merger policy, i.e., $\widetilde{\phi}_{d}^{c}<\widetilde{\phi}^{c}$. The incentive benefits of diversification can be so large that the result derived in Proposition 4 is reversed, and weaker competition leads to a more lenient merger policy, i.e., $\widetilde{\phi}^{b}>\widetilde{\phi}_{d}^{c}$.

It is worth noting that a higher degree of complementarity softens the optimal merger policy irrespective of the mode of competition, since $\frac{\partial \widetilde{\phi}^{b}}{\partial \gamma}>0$ and $\frac{\partial \widetilde{\phi}_{d}^{c}}{\partial \gamma}>0$ for $\gamma<0$. Proposition 6 indicates that the optimal merger policy under Cournot competition is more lenient than under Bertrand competition if $\theta_{h}<\widetilde{\theta}_{h}(\gamma)$. As $\widetilde{\theta}_{h}$ increases with $\gamma$, a higher degree of complementarity strengthens this condition. As a result, when goods are not close complements, the aforementioned incentive benefits of diversification into a weakly competitive segment outweigh the allocative benefits of intense competition derived in Propositions 2 and 4 . When the degree of complementarity is high enough, the opposite may occur, and the latter benefits tend to prevail.

The result of a more lenient merger policy under Cournot competition is even stronger in the presence of economies of scope between regulated and unregulated activities. As Calzolari and Scarpa (2011) show, a lower regulated quantity that follows from cost misrepresentation increases the (marginal) costs of unregulated operations, which induces the Cournot competitors of the diversified regulated firm to expand their production. Consequently, Cournot competition mitigates the regulator's incentive problem and leads to a softer merger challenge rule. 


\section{Robustness}

We now discuss some assumptions of the model in order to gain insights into the robustness of the results.

\subsection{Efficiency gains}

Following the main literature on uncertain efficiency gains (e.g., Amir et al. 2009; Choné and Linnemer 2008), we assume that antitrust authorities and merging firms share the same beliefs about the realization of synergies. In practice, antitrust authorities seek to extract any superior information of the merging firms with the request of convincing documentation about efficiency claims. The common knowledge probability of efficiency gains can be thought of as the average value of comparable mergers or post-merger simulations accepted by antitrust authorities.

Furthermore, in our model the main informational advantage of merging firms is that they privately learn the realization of post-merger costs. Abstracting from the complexities that arise from regulatory limited commitment, one might claim that by its very nature this type of informational asymmetry is transitory, since the regulator could revise the regulatory policy and remove any distortions in the light of the information acquired about efficiency gains. In this sense, our model provides a short-run analysis. As Amir et al. (2009) argue, this approach is justified since the short-run period is the main focus of merger investigations. ${ }^{20}$ Moreover, our main results hinge upon the presence of asymmetric information after the merger, which does not necessarily arise from synergies. Practitioners are aware that a merger between regulated firms tends to aggravate the regulator's informational problem. This is because after the merger it becomes more cumbersome to use benchmarking mechanisms in order to discipline the regulated firm's behavior.

\subsection{Firms' incentives to merge}

Throughout the analysis, we do not explicitly deal with the merger decision of regulated firms. This point definitely deserves some discussion. In the absence of diversification, it is immediate to see that regulated firms have an incentive to merge, since the merger entails (expected) informational rents from privileged knowledge of efficiency gains.

This result clearly extends to the case of diversification into a Bertrand segment. To explore the firms' incentives to merge under Cournot competition, we compare the expected profits from the merger with the profits in the absence of the merger, which only arise from competitive activities. Using the binding incentive constraint (12), a merger is profitable if and only if

$$
E\left[\widetilde{\pi}_{r}^{m c d}+\pi^{11}\left(\widetilde{q}_{1 r}^{m c d}\right)+\pi^{21}\left(\widetilde{q}_{2 r}^{m c d}\right)\right]=\nu \Delta \theta\left(\widetilde{q}_{1 r l}^{m c d}\right)^{2}+2 \pi^{11}\left(\widetilde{q}_{1 r l}^{m c d}\right)>2 \pi^{11}\left(q_{1 r}^{c}\right) .
$$

Since the post-merger regulated output of the inefficient firm is lower than the output without the merger, $\widetilde{q}_{i r l}^{m c d}<q_{i r}^{c}, i=1,2$, a merger is always proposed when goods are substitutes. This is because the merging firms obtain (expected) informational rents from regulated activities

\footnotetext{
${ }^{20}$ A long-run analysis is much more demanding, since it requires the identification of other potential contributing factors, such as industry-specific or economy-wide shocks. This explains why most empirical studies consider horizons extending only 3 to 5 years.
} 
and higher competitive profits due to downward regulated output distortions. When goods are complements, the post-merger reduction in regulated production of the inefficient firm dampens competitive profits. Therefore, a merger is profitable if the informational rents from regulated activities outweigh the lower profits from competitive operations.

\section{Concluding remarks and policy implications}

In this paper we examine the welfare implications of a merger between regulated firms in the presence of two main informational problems, namely, uncertainty and asymmetric information about efficiency gains, when regulated firms interact with unregulated suppliers that operate in a competitive segment of the market.

The merger between regulated firms entails a trade-off between the benefits of potential efficiency gains from joint production and the costs of distortions in the regulatory policy due to informational problems about post-merger costs. We show that, as a result of this trade-off, the optimal merger policy depends on the intensity of competition in the unregulated part of the market. In particular, more severe competition makes the optimal merger policy more lenient with merging regulated firms. The rationale for this result is that more severe competition induces firms to be more responsive to changes in their demand driven by distortions in the regulatory policy due to informational problems. This reduces the allocative costs of regulatory distortions and softens merger policy.

The optimal merger policy is also crucially affected by the possibility that regulated firms diversify into the unregulated part of the market. When regulated and unregulated goods exhibit some degree of complementarity, the diversified merged firm has a lower incentive to manipulate its private information about efficiencies from the merger, since a lower regulated quantity due to cost misrepresentation translates into lower demand and lower profits in the competitive segment. Therefore, under complementarity, the regulated firm's internalization of competitive profits relaxes the regulator's incentive problem, and weaker competition (which generates higher profits) in the unregulated part of the market can lead to a more lenient merger policy.

Our analysis provides support for the view of practitioners and policy makers that the effects of mergers on regulatory policies deserve adequate investigation when assessing mergers between regulated firms. For instance, the US Federal Energy Regulatory Commission (FERC), whose authorization is required for mergers and consolidations of energy utilities, emphasized in the Order issued on February 16, 2012 that it considers the impact on rates and regulation when scrutinizing a merger. ${ }^{21}$

It is well established in the theoretical and practical debate that mergers in unregulated industries entail a trade-off between efficiency gains from joint production and enhanced market power of merging firms, which results from a reduction in the number of rivals competing in the market. Our analysis recommends that the study of the intensity of competition should be extended to markets where merging regulated firms interact with unregulated suppliers.

Specifically, our results suggest that the merger policy involving regulated firms should be more lenient in industries where liberalized segments of the market are characterized by intense

\footnotetext{
${ }^{21}$ See http://ferc.gov/whats-new/comm-meet/2012/021612/E-2.pdf.
} 
competition. This can be the case in the telecommunications and energy sectors where network operations are under regulatory control and retail services are highly competitive. In the US, Canada and Europe, consumers can sometimes choose to purchase electricity and gas either in the captive market from a regulated utility or in the free market from competitive suppliers.

In some circumstances, however, competition in liberalized segments of the market is weak, for instance because of severe capacity constraints. This can occur in transportation, telecommunications and energy sectors when unregulated suppliers must undertake huge investments. If regulated firms engage in the provision of unregulated services that are substitutes for the regulated ones, antitrust authorities should toughen their stance towards mergers between regulated firms. This could apply to regulated transportation utilities that also provide unregulated bus services or regulated energy utilities which are also active in the free market. Conversely, if regulated firms also provide goods which are complements for the regulated ones, the merger between regulated firms should be assessed more favorably. This can be the case of energy network utilities which also supply retail services, or local exchange carriers which also provide long-distance telephone services or telephone equipment.

This conclusion warrants some remarks. In our analysis, we consider mergers between regulated firms which are active in different regions and may diversify into a competitive segment of the market where they operate. When a regulated firm expands into a competitive segment of the market where the other firm is established, a merger clearly exhibits an anticompetitive concern stemming from the enhanced market power in the unregulated segment. In this case, antitrust authorities might approve the merger conditionally upon some structural remedies, such as the divestiture of one competitive subsidiary.

Acknowledgments We thank Helmut Bester, Matthias Dahm, Philipp Heller, Martin Peitz, Martin Pollrich, Larry Samuelson, Jan-Peter Siedlarek, Roland Strausz and Cédric Wasser for helpful comments and suggestions. We are also grateful to the participants at CRESSE Conference 2013 in Corfu, SFB-TR15 Conference 2014 in Mannheim, CLEEN Workshop 2014 in Norwich and CCRP Workshop 2014 in Barcelona.

\section{Appendix}

This appendix collects the proofs.

Proof of Lemma 1. Since the maximand decreases in $\pi_{i}$, we find $\pi_{i}^{b}=\pi_{i}^{c}=0, i=1,2$, in equilibrium. Under Bertrand competition, using the second-stage outcome $q_{i u}^{b}\left(q_{i r}\right)=\alpha-c-\gamma q_{i r}$ with $p_{i u}^{b}=c$ and taking the first-order condition for $q_{i r}$ yields $(1-\gamma)(\alpha-c)-\left(1-\gamma^{2}\right) q_{i r}=0$, $i=1,2$. Under Cournot competition, using the second-stage outcome $q_{i u}^{c}\left(q_{i r}\right)=\frac{2}{3}\left(\alpha-c-\gamma q_{i r}\right)$ with $p_{i u}^{c}=\alpha-q_{i u}^{c}()-.\gamma q_{i r}$ and taking the first-order condition for $q_{i r}$ yields $(9-4 \gamma)(\alpha-c)-$ $\left(9-4 \gamma^{2}\right) q_{i r}=0, i=1,2$. Standard substitutions entail the results collected in the lemma.

Proof of Lemma 2. Since the maximand decreases in $\pi$, we find $\pi^{m b}=\pi^{m c}=0$, in equilibrium. Under Bertrand competition, using the second-stage outcome $q_{i u}^{b}\left(q_{i r}\right)=\alpha-c-\gamma q_{i r}$ with $p_{i u}^{b}=c$ and taking the first-order condition for $q_{i r}$ yields $(1-\gamma)(\alpha-c)-\left(1-\gamma^{2}\right) q_{i r}+\theta q_{j r}=0$, $i, j=1,2, i \neq j$. Under Cournot competition, using the second-stage outcome $q_{i u}^{c}\left(q_{i r}\right)=$ 
$\frac{2}{3}\left(\alpha-c-\gamma q_{i r}\right)$ with $p_{i u}^{c}=\alpha-q_{i u}^{c}()-.\gamma q_{i r}$ and taking the first-order condition for $q_{\text {ir }}$ yields $(9-4 \gamma)(\alpha-c)-\left(9-4 \gamma^{2}\right) q_{i r}+9 \theta q_{j r}=0, i, j=1,2, i \neq j$. Standard substitutions entail the results collected in the lemma.

Proof of Lemma 3. Using the results in Lemmas 1 and 2, we find that, under Bertrand competition, welfare without the merger is $C S^{b}=\frac{2(\alpha-c)^{2}}{1+\gamma}$ and welfare with the merger is $C S^{m b}=\frac{(2-2 \gamma-\theta)(\alpha-c)^{2}}{1-\gamma^{2}-\theta}$. Taking the difference between $C S^{m b}$ and $C S^{b}$ yields $\frac{(1-\gamma)(\alpha-c)^{2} \theta}{\left(1-\gamma^{2}-\theta\right)(1+\gamma)}>0$ if and only if $\theta=\theta_{h}>0$. Analogously, under Cournot competition, taking the difference between welfare with merger $C S^{m c}=\frac{4(\alpha-c)^{2}}{9}+\frac{(9-4 \gamma)^{2}(\alpha-c)^{2}}{9\left(9-4 \gamma^{2}-9 \theta\right)}$ and welfare without merger $C S^{c}=$ $\frac{4(\alpha-c)^{2}}{9}+\frac{(9-4 \gamma)^{2}(\alpha-c)^{2}}{9\left(9-4 \gamma^{2}\right)}$ yields $\frac{(9-4 \gamma)^{2}(\alpha-c)^{2} \theta}{\left(9-4 \gamma^{2}-9 \theta\right)\left(9-4 \gamma^{2}\right)}>0$ if and only if $\theta=\theta_{h}>0$.

Proof of Proposition 1. Using the results derived in the proof of Lemma 3, we find that, under Bertrand competition, expected welfare from the merger is $E\left[C S^{m b}\right]=\nu \frac{\left(2-2 \gamma-\theta_{h}\right)(\alpha-c)^{2}}{1-\gamma^{2}-\theta_{h}}+$ $(1-\nu) \frac{\left(2-2 \gamma-\theta_{l}\right)(\alpha-c)^{2}}{1-\gamma^{2}-\theta_{l}}$. Standard computations yield $E\left[C S^{m b}\right]>C S^{b}$ if and only if condition (5) in the proposition holds. Analogously, under Cournot competition, expected welfare from the merger is $E\left[C S^{m c}\right]=\frac{4(\alpha-c)^{2}}{9}+\nu \frac{(9-4 \gamma)^{2}(\alpha-c)^{2}}{9\left(9-4 \gamma^{2}-9 \theta_{h}\right)}+(1-\nu) \frac{(9-4 \gamma)^{2}(\alpha-c)^{2}}{9\left(9-4 \gamma^{2}-9 \theta_{l}\right)}$. Standard computations yield $E\left[C S^{m c}\right]>C S^{c}$ if and only if condition (6) in the proposition holds.

Proof of Proposition 2. The proof follows from the comparison between (5) and (6). The non-negativity conditions on quantities entail $\nu^{b} \in(0,1)$ and $\nu^{c} \in(0,1)$.

Proof of Lemma 4. The incentive constraint (7) and the participation constraint $\pi_{r l} \geq 0$ imply $\pi_{r h} \geq 0$, which is therefore slack in equilibrium. Moreover, (7) and $\pi_{r l} \geq 0$ must be binding at the optimal contract, otherwise the regulator could increase welfare via an adequate reduction in the firm's transfers. We check ex post that the incentive constraint (8) is satisfied, which is the case if and only if the monotonicity condition $q_{1 r h} q_{2 r h} \geq q_{1 r l} q_{2 r l}$ (that follows from adding (7) and (8)) holds. Under Bertrand competition, using the second-stage outcome $q_{i u}^{b}\left(q_{i r}\right)=\alpha-c-\gamma q_{i r}$ with $p_{i u}^{b}=c$ and taking the first-order conditions for $q_{i r h}$ and $q_{i r l}$ yields $(1-\gamma)(\alpha-c)-\left(1-\gamma^{2}\right) q_{i r h}+\theta_{h} q_{j r h}=0$ and $(1-\gamma)(\alpha-c)-\left(1-\gamma^{2}\right) q_{i r l}+\theta_{l} q_{j r l}-\Delta \theta \phi q_{j r l}=0$, $i, j=1,2, i \neq j$. Under Cournot competition, using $q_{i u}^{c}\left(q_{i r}\right)=\frac{2}{3}\left(\alpha-c-\gamma q_{i r}\right)$ and $p_{i u}^{c}=$ $\alpha-q_{i u}^{c}()-.\gamma q_{i r}$, we find after some manipulation $(9-4 \gamma)(\alpha-c)-\left(9-4 \gamma^{2}\right) q_{i r h}+9 \theta_{h} q_{j r h}=0$ and $(9-4 \gamma)(\alpha-c)-\left(9-4 \gamma^{2}\right) q_{i r l}+9 \theta_{l} q_{j r l}-9 \Delta \theta \phi q_{j r l}=0, i, j=1,2, i \neq j$. Usual substitutions imply the results in the lemma. Since the condition $q_{1 r h} q_{2 r h} \geq q_{1 r l} q_{2 r l}$ holds, the incentive constraint (8) is also satisfied.

Proof of Proposition 3. From Lemma 4 we find that expected welfare $\widetilde{C S}^{m b}$ from the merger in the presence of Bertrand competition can be written after some manipulation in the following way

$$
\begin{aligned}
& (\alpha-c)^{2}+\frac{\nu(1-\gamma)^{2}(\alpha-c)^{2}}{1-\gamma^{2}-\theta_{h}}+\frac{(1-\nu)(1-\gamma)^{2}(\alpha-c)^{2}}{1-\gamma^{2}-\theta_{l}+\Delta \theta \phi} \\
& =(\alpha-c)^{2}+\frac{\left(1-\gamma^{2}-\theta_{h}+\Delta \theta \phi\right)(1-\gamma)^{2}(\alpha-c)^{2}}{\left(1-\gamma^{2}-\theta_{h}\right)\left(1-\gamma^{2}-\theta_{l}+\Delta \theta \phi\right)}
\end{aligned}
$$

From Lemma 1 welfare without the merger is $C S^{b}=\frac{2(\alpha-c)^{2}}{1+\gamma}$. It follows that $\widetilde{C S}^{m b}>C S^{b}$ if and only if condition (10) in the proposition holds. The non-negativity conditions on quantities 
entail $\widetilde{\nu}^{b} \in\left(\nu^{b}, 1\right)$.

Expected welfare $\widetilde{C S}^{m c}$ from the merger in the presence of Cournot competition can be written after some manipulation as follows

$$
\begin{aligned}
& \frac{4(\alpha-c)^{2}}{9}+\frac{\nu(9-4 \gamma)^{2}(\alpha-c)^{2}}{9\left(9-4 \gamma^{2}-9 \theta_{h}\right)}+\frac{(1-\nu)(9-4 \gamma)^{2}(\alpha-c)^{2}}{9\left(9-4 \gamma^{2}-9 \theta_{l}+9 \Delta \theta \phi\right)} \\
& =\frac{4(\alpha-c)^{2}}{9}+\frac{\left(9-4 \gamma^{2}-9 \theta_{h}+9 \Delta \theta \phi\right)(9-4 \gamma)^{2}(\alpha-c)^{2}}{9\left(9-4 \gamma^{2}-9 \theta_{h}\right)\left(9-4 \gamma^{2}-9 \theta_{l}+9 \Delta \theta \phi\right)} .
\end{aligned}
$$

From Lemma 1 we find that welfare without the merger is $C S^{c}=\frac{4(\alpha-c)^{2}}{9}+\frac{(9-4 \gamma)^{2}(\alpha-c)^{2}}{9\left(9-4 \gamma^{2}\right)}$. It follows that $\widetilde{C S}^{m c}>C S^{c}$ if and only if condition (11) in the proposition holds. The nonnegativity conditions on quantities entail $\widetilde{\nu}^{c} \in\left(\nu^{c}, 1\right)$.

Proof of Proposition 4. Using (5) and (10) yields $\widetilde{\nu}^{b}-\nu^{b}=-\frac{\left(1-\gamma^{2}-\theta_{h}\right)^{2} \theta_{h} \theta_{l}}{\left(1-\gamma^{2}\right)\left[\theta_{h}^{2}-\left(1-\gamma^{2}\right) \theta_{l}\right] \Delta \theta}$. Moreover, we find from (6) and (11) that $\widetilde{\nu}^{c}-\nu^{c}=-\frac{\left(9-4 \gamma^{2}-9 \theta_{h}\right)^{2} \theta_{h} \theta_{l}}{\left(9-4 \gamma^{2}\right)\left[9 \theta_{h}^{2}-\left(9-4 \gamma^{2}\right) \theta_{l}\right] \Delta \theta}$. Standard computations entail $\widetilde{\nu}^{c}-\nu^{c} \geq \widetilde{\nu}^{b}-\nu^{b}$, where the equality holds if and only if $\gamma=0$. Combining terms yields the result in the proposition.

Proof of Lemma 5. In line with the proof of Lemma 4, we consider the incentive constraint (12) and the participation constraint $\pi_{r l} \geq 0$ binding at the optimal contract, otherwise the regulator could increase welfare via an adequate reduction in the firm's transfers. We check ex post that the monotonicity condition (14) and the participation constraint $\pi_{r h} \geq 0$ hold. Using $q_{i u}^{c}\left(q_{i r}\right)=\frac{2}{3}\left(\alpha-c-\gamma q_{i r}\right)$ and $p_{i u}^{c}=\alpha-q_{i u}^{c}()-.\gamma q_{i r}$, the first-order conditions for $q_{i r h}$ and $q_{i r l}$ are respectively $(9-6 \gamma)(\alpha-c)-\left(9-4 \gamma^{2}\right) q_{i r h}+9 \theta_{h} q_{j r h}+2 \gamma^{2} q_{i r h}=0$ and $(9-4 \gamma)(\alpha-c)-$ $\left(9-4 \gamma^{2}\right) q_{i r l}+9 \theta_{l} q_{j r l}-9 \Delta \theta \phi q_{j r l}-2 \gamma^{2} \phi q_{i r l}=0, i, j=1,2, i \neq j$. Usual substitutions imply the results in the lemma. For $\gamma \geq 0$, sufficient condition for the monotonicity condition (14) to be satisfied is $\theta_{l} \leq \frac{1}{3}(\sqrt{3}-2)$. Alternatively, we must have $\theta_{h} \geq 2 \gamma \frac{1-\gamma}{9-4 \gamma}$. For $\gamma<0$, (14) is always satisfied. Moreover, for $\gamma \geq 0$, the participation constraint $\pi_{r h} \geq 0$ is always fulfilled. For $\gamma<0$, sufficient, but not necessary, condition for $\pi_{r h} \geq 0$ to be satisfied is that $|\gamma|$ is not too high.

Proof of Proposition 5. From Lemma 5 we find that expected welfare $\widetilde{C S}^{\text {mcd }}$ from the merger can be written after some manipulation in the following way

$$
\frac{4(\alpha-c)^{2}}{9}+\frac{\nu(3-2 \gamma)^{2}(\alpha-c)^{2}}{3\left(3-2 \gamma^{2}-3 \theta_{h}\right)}+\frac{(1-\nu)(9-4 \gamma+2 \gamma \phi)^{2}(\alpha-c)^{2}}{9\left[9-4 \gamma^{2}-9 \theta_{l}+\left(2 \gamma^{2}+9 \Delta \theta\right) \phi\right]} .
$$

Combining terms yields

$$
\frac{4(\alpha-c)^{2}}{9}+\frac{\left[(9-4 \gamma)^{2}+4 \gamma^{2} \phi\right]\left(3-2 \gamma^{2}-3 \theta_{h}\right)+3(3-2 \gamma)^{2}\left(2 \gamma^{2}+9 \Delta \theta\right) \phi}{9\left(3-2 \gamma^{2}-3 \theta_{h}\right)\left[9-4 \gamma^{2}-9 \theta_{l}+\left(2 \gamma^{2}+9 \Delta \theta\right) \phi\right]}(\alpha-c)^{2} .
$$

From Lemma 1 we find that welfare without the merger is $C S^{c}=\frac{4(\alpha-c)^{2}}{9}+\frac{(9-4 \gamma)^{2}(\alpha-c)^{2}}{9\left(9-4 \gamma^{2}\right)}$. Taking 
the difference between $\widetilde{C S}^{\text {mcd }}$ and $C S^{c}$ yields after some manipulation

$$
\begin{aligned}
& 9(9-4 \gamma)^{2}\left(3-2 \gamma^{2}-3 \theta_{h}\right) \theta_{l}+\phi\left\{\Delta \theta\left[2 \gamma\left(57 \gamma-8 \gamma^{3}-54\right)+3 \theta_{h}(9-4 \gamma)^{2}\right]\right. \\
& \left.+2 \gamma^{2}\left[6(1-\gamma)^{2}+\theta_{h}\left(21+8 \gamma^{2}-24 \gamma\right)\right]\right\}
\end{aligned}
$$

which is negative if the expression in curly brackets is negative. When goods are substitutes, i.e., $\gamma \geq 0$, this is the case for $\theta_{h} \leq \theta_{h}^{*}(\gamma)$, with

$\theta_{h}^{*} \equiv \frac{4 \gamma-4 \gamma^{2}+9 \theta_{l}-4 \gamma \theta_{l}}{2(9-4 \gamma)}+\frac{\sqrt{9 \theta_{l}\left[8 \gamma\left(2 \gamma-3 \theta_{l}\right)-3\left(8 \gamma-9 \theta_{l}\right)\right]+16 \gamma^{2} \theta_{l}\left[2 \gamma(3-2 \gamma)+3 \theta_{l}\right]}}{2 \sqrt{3}(9-4 \gamma)} \geq 0$,

where the equality holds if and only if $\gamma=0$. For $\theta_{h}>\theta_{h}^{*}$, we have $\widetilde{C S}^{m c d}>C S^{c}$ if and only if condition (15) in the proposition holds. Under complementarity, i.e., $\gamma<0$, the expression in curly brackets is always positive. Then, we find $\widetilde{C S}^{m c d}>C S^{c}$ if and only if condition (15) holds.

Proof of Proposition 6. Taking the difference between $\widetilde{C S}^{m c d}$ in (19) and $\widetilde{C S}^{m c}$ in (18) yields $\widetilde{C S}^{m c d}-\widetilde{C S}^{m c} \lesseqgtr 0$ if and only if $\gamma \gtreqless 0$. This is because the regulator faces the same maximization problem, subject to the same participation constraints, while the incentive constraint (12) is stricter (weaker) than $(7)$ for $\gamma>(<) 0$ (the constraints (8) and (13) are implied by the monotonicity condition (14)). Then, we have $\widetilde{\phi}_{d}^{c} \gtreqless \widetilde{\phi}^{c}$ if and only if $\gamma \gtreqless 0$. Alternatively, this result follows from the comparison between (15) and (17). Using Proposition 4 , we find for $\gamma \geq 0$ that $\widetilde{\phi}_{d}^{c} \geq \widetilde{\phi}^{c} \geq \widetilde{\phi}^{b}$ (where the equality holds if and only if $\gamma=0$ ). For $\gamma<0$, using (15) and (16), we find $\widetilde{\phi}^{b}>\widetilde{\phi}_{d}^{c}$ if $\theta_{h}<\widetilde{\theta}_{h}(\gamma)$, where

$$
\widetilde{\theta}_{h} \equiv \frac{2\left(1-\gamma^{2}\right)\left(54-57 \gamma+8 \gamma^{3}\right)}{3[36-\gamma(65-24 \gamma)]}>0
$$

Standard computations yield $\frac{\partial \widetilde{\theta}_{h}}{\partial \gamma}=6 \frac{(65-48 \gamma)\left(54-57 \gamma-54 \gamma^{2}+65 \gamma^{3}-8 \gamma^{5}\right)}{\left(108-195 \gamma+72 \gamma^{2}\right)^{2}}-2 \frac{57+108 \gamma-195 \gamma^{2}+40 \gamma^{4}}{108-195 \gamma+72 \gamma^{2}}>0$, where the inequality follows from the assumptions on the parameters of the model.

\section{References}

Amir, R., Diamantoudi, E., and L. Xue (2009), "Merger Performance under Uncertain Efficiency Gains," International Journal of Industrial Organization, 27(2), 264-273.

Armstrong, M., and D. E. M. Sappington (2007), "Recent Developments in the Theory of Regulation," in: M. Armstrong, and R. Porter (eds.), Handbook of Industrial Organization, Elsevier Science Publishers, Amsterdam, pp. 1557-1700.

Baron, D. P., and D. Besanko (1992), "Information, Control, and Organizational Structure," Journal of Economics and Management Strategy, 1(2), 237-275.

Baron, D. P., and R. B. Myerson (1982), "Regulating a Monopolist with Unknown Costs," Econometrica, 50(4), 911-930. 
Bitzan, J. D., and W. W. Wilson (2007), "Industry Costs and Consolidation: Efficiency Gains and Mergers in the U.S. Railroad Industry," Review of Industrial Organization, 30(2), 81-105.

Calzolari, G., and C. Scarpa (2009), "Footloose Monopolies: Regulating a 'National Champion'," Journal of Economics and Management Strategy, 18(4), 1179-1214.

Calzolari, G., and C. Scarpa (2011), "On Regulation and Competition: Pros and Cons of a Diversified Monopolist," mimeo.

Choné, P., and L. Linnemer (2008), "Assessing Horizontal Mergers under Uncertain Efficiency Gains," International Journal of Industrial Organization, 26(4), 913-929.

Cox, A. J., and J. Portes (1998), "Mergers in Regulated Industries: The Uses and Abuses of Event Studies," Journal of Regulatory Economics, 14(3), 281-304.

Cremer, H., and P. De Donder (2013), "Network Investment under Legal and Ownership Unbundling," Review of Network Economics, 12(1), 27-59.

Farrell, J., and C. Shapiro (2001), "Scale Economies and Synergies in Horizontal Merger Analysis," Antitrust Law Journal, 68(3), 685-710.

Gilbert, R. J., and M. H. Riordan (1995), "Regulating Complementary Products: A Comparative Institutional Analysis," Rand Journal of Economics, 26(2), 243-256.

Gugler, K., Mueller, D. C., Yurtoglu, B. B., and C. Zulehner (2003), "The Effects of Mergers: An International Comparison," International Journal of Industrial Organization, 21(5), 625-654.

Hamada, K. (2012), "Uncertainty and Horizontal Mergers," Journal of Institutional and Theoretical Economics, 168(2), 252-265.

Höffler, F., and S. Kranz (2011), "Legal Unbundling can be a Golden Mean between Vertical Integration and Ownership Separation," International Journal of Industrial Organization, 29(5), 576-588.

Iossa, E. (1999), "Informative Externalities and Pricing in Regulated Multiproduct Industries," Journal of Industrial Economics, 47(2), 195-219.

Kwoka, J., and M. Pollitt (2010), "Do Mergers Improve Efficiency? Evidence from Restructuring the US Electric Power Sector," International Journal of Industrial Organization, 28(6), 645-656.

Motta, M. (2004), Competition Policy: Theory and Practice, Cambridge University Press, Cambridge, MA.

Myerson, R. B. (1979), "Incentive Compatibility and the Bargaining Problem," Econometrica, 47(1), 61-74.

Neven, D. J., and L. H. Röller (2005), "Consumer Surplus vs. Welfare Standard in a Political Economy Model of Merger Control," International Journal of Industrial Organization, 23(9-10), 829-848. 
Sibley, D. S., and D. L. Weisman (1998), "Raising Rivals' Costs: The Entry of an Upstream Monopolist into Downstream Markets," Information Economics and Policy, 10(4), 451-470.

Sidak, J. G., and D. Spulber (1998), Deregulatory Takings and the Regulatory Contract, Cambridge University Press, Cambridge, MA.

Singh, N., and X. Vives (1984), "Price and Quantity Competition in a Differentiated Duopoly," Rand Journal of Economics, 15(4), 546-554.

Torres, M., and C. J. Morrison Paul (2006), "Driving Forces for Consolidation or Fragmentation of the US Water Utility Industry: A Cost Function Approach with Endogenous Output," Journal of Urban Economics, 59(1), 104-120.

Vickers, J. (1995), "Competition and Regulation in Vertically Related Markets," Review of Economic Studies, 62(1), 1-17.

White, L. J. (1987), "Antitrust and Merger Policy: A Review and Critique," Journal of Economic Perspectives, 1(2), 13-22.

Williamson, O. E. (1968), "Economies as an Antitrust Defense: The Welfare Trade-offs," American Economic Review, 58(1), 18-36. 